\title{
Influence of Paranormal beliefs on Psychopathology in a Cross- Cultural Society
}

\author{
Sulaiman Olanrewaju Adebayo, Oluyemi Stephen ILORI \\ Department of Psychology Faculty of the Social Sciences, Ekiti State Ekiti State University, Ado-Ekiti. \\ Department of Psychology Faculty of the Social Sciences, Ekiti State Ekit State University, Ado-Ekitii.
}

\begin{abstract}
The purpose of this study was to determine if there would be significant main and interaction influence of paranormal beliefs and culture on incidence of psychopathology among a non-psychotic population. A survey research was carried out using a purposive non-probability sampling method drawing the sample from two ethnic groups; Yoruba and Igbo. They consisted of two hundred and four respondents with 78 adolescent and 126 adults with the age range of 14 and 65 years, 103 male and 101 female, 132 Christians, 66 Muslims and 6 traditional religious adherents, 107 Yoruba and 98 Igbo; all of which attained the minimum educational level of Junior Secondary School Certificate, who responded to Revised Paranormal Belief Scale (Tobacyk, 1988) and the General Health Questionnaire (Goldberg, 1978).Using Factorial Design, 2 X 2 ANOVA and Independent t-test to analyse the data, results indicated that paranormal beliefs significantly influenced anxiety and depression dimensions of psychopathology. It was also revealed that there was a significant main influence of culture on anxiety and depression. Also observed was a significant difference between the two ethnic groups, Yoruba and Igbo, on paranormal belief and incidence of psychopathology. It was therefore concluded that paranormal beliefs and culture have significant main influence on incidence of psychopathological symptoms.
\end{abstract}

Key words: Paranormal, beliefs, cross-culture, psychopathology

\section{Introduction}

There is a general belief among the Yoruba and Igbo people of Western and Eastern Nigeria that death or ill-health does not just occur to anyone naturally without certain supernatural or invisible forces being responsible for either the death or ill-health. This is true of most mental illness that are usually considered or linked to such scientifically inexplicable forces, regardless of whatever empirical or medical diagnosis that might have been carried out. Tsa-Tsala (1997) posits that every disease is systematically acknowledged as having a supernatural origin such as the grief of ancestors or divinities,the practices of sorcery and various evil spells. This position goes to say that Africans do not relate the origin of disease to biological causes alone but see it as a social phenomena and that disease can be transmitted from one generation to another as long as the associated stains of a fault have not been cleared. It is common therefore to hear people speaking of psychic afflictions, casting of spells, attack of witchcrafts, violation of community taboos, offending ancestral spirits and many other events that fall within the paranormal and cultural beliefs.

The term paranormal belief is used to describe phenomena which if authentic, but violate the basic principles of science (Broad, 1953; Tobacyk, 1988). Paranormal phenomena are associated with myths and rituals. However, no scientific basis for such phenomena had been found and perhaps the reason why they are not yet included in the psychiatric classification systems. The term paranormal also refers to hypothesized processes that in principle are "physically impossible" or outside the realm of human capabilities as presently conceived by conventional scientists (Thalbourne, 1994). However, the fact that such events seemed physically impossible does not mean that they are not effectively felt by the persons concerned. Therefore, it may mean that our knowledge in that regard is nevertheless not adequate.

The concept of culture has also been implicated in the incidence of psychopathology. The term culture has been defined as a dynamic system of rules, explicit and implicit, established by groups in order to ensure their survival. It involves attitudes, values, beliefs, norms, and behaviours, shared by a group but harboured differently by each specific unit within the group, which is also communicated across generations, relatively stable but with the potential to change across time (Murdock, 1971). While trying to define culture, Triandis (1972) coined the term subjective culture and defined it as consisting of the attitudes, values, beliefs, norms and behaviours which form the contents of the mind of every individual who lives in that culture. It is believed that these aspects of culture also exists as a social consciousness which stand above and beyond individuals.

Cultural beliefs are learned phenomena in social interactions (Bandura, 1986). Bandura posits that as people grow older, they learn specific behaviour and patterns of activities appropriate and inappropriate for their 
culture, and they either adopt or reject values as they reach adolescent stage when most behaviours have the probability of either being discarded or become permanent. Understanding more about culture can be beneficial to whosoever is working in any organization most especially in the health sector for the purpose of understanding some invisible cultural characteristics that each client may hold which may influence their mental state of health. The knowledge of such cultural orientation will help the physician to tackle any problem using such cultural values as psycho-educational tools. Levine (2009) stated that culture and personality studies are primarily concerned with those aspects in which a man is like some other man; particularly his fellow group members, in contrast to members of other groups. In line with this preposition, Levine (2009) extracted from intercultural experience the underlisted plausible assumptions about cultural variation in individual dispositions.

a. some culturally distinctive patterns of thought and feeling are not readily accessible to verbal formulative or voluntary control but seem to influence the individual decision about regulating himself and adapting to his environment.

b. these patterns are not easily reversed even when the individual is outside the cultural environment that normally reinforces them.

c. the individual can adapt behaviourally to the demand of novel cultural environments without eliminating these patterns of thoughts, feelings, although their behavioural manifestation may be temporarily inhibited or situationally restricted.

In the context of cultural differences between the Igbos and Yorubas, it has been observed that inspite of sustained social interaction between the two ethnic groups, there still exists distinct variation in so many aspects of their lives such as differences in behaviours, music, dance, food and clothing, art, rituals, traditions, and heritage. Culture also refers to so many different aspect of life, as depicted in the work of Murdock, Ford, and Hudson (1971) which described 79 different aspects of life but which Barry (1980) rearranged into eight broad categories as reported by Berry (1992) as: General characteristics, food and clothing, housing and technology, economy and transportation, individual and family activities, community and government, welfare, religion and science, sex and the life circle. Culture therefore, according to Malpass (1993) in its truest and broadest sense, cannot be swallowed in a single gulp-not in a book, not in a university course, not in any training programme, because culture in all its richness and complexity is huge. Also culture according to Matsumoto (2002) is "Fuzzy"

in that it provides no hard-and-fast rules to determine what it is or who belongs to that culture and that culture is a sociopsychological construct, a sharing across people of psychological phenomena such as values, attitudes, beliefs and behaviours. Hence what defines member of the same culture is whether they share these psychological phenomena and what distinguishes members of one culture from another is the absence of these shared phenomena.

Therefore, taken above characteristics of cross-cultural conceptual attributes into consideration, it becomes obvious that the Yorubas of the Western region and the Igbos of the Eastern region of Nigeria are culturally different.

Culture has attracted several definitions, Samova (1971) and Markel (2009) see it as the accumulative deposit of knowledge, experience, meanings, beliefs, values, attitudes, religions, concepts of self, the universe, and selfuniverse relationships, hierarchies of status, role expectations, spatial relations, and time concepts acquired by large group of people in the course of generations through individuals and group striving. Culture manifests itself both in patterns of language and thought and form of activity and behaviour. These patterns become models for common adaptive acts and styles of expressive behaviour which enable people to live in a society within a given state of technical development.

Culture has an overwhelming influence on the lives of its people. It develops institutions that enforce the prescribed set of conduct and norms in a society. The process of effecting this is usually sanctioned by the culture as developed by the society itself. Therefore, in any society according to Benedict (1961),

no Man ever looks at the world with pristine eyes. He sees it edited by definite set of customs and institutions and ways of thinking. Even in his philosophical probing, he cannot go beyond these stereotypes, his concepts of the true and the false will still have reference to his particular traditional customs. The members of a society are basically what their culture has made of them. This according to Benedict (1961) is because the life-history of the individual is first and foremost an accommodation of the patterns and 
standards traditionally handed down in his community through generations. From the moment of his birth, the custom in which he is born shapes his experience and by the time he is able to take part in its activities, its habits are his habits, its beliefs are his beliefs, its impossibilities are his impossibilities.

In the above regard, culture serves as a tool in understanding and predicting human behaviour in many ways. Bell (1961) also posits that a recognition and knowledge of the nature of culture is basic to the understanding of human behaviour. It acts as tools for forecasting behaviour in many specific ways. The knowledge removes the mystery which surrounds the behaviour of people from other cultural groups. Therefore similarity of personality in inter-cultural group and similarity of attitudes can cause similar relationship encounter. In other words, individuals with dissimilar attitudes and beliefs are seldom attracted to each other and may not be able to sustain meaningful interaction. Possibly this is why Smith (1973) observed that there seems to be more tension in strange interaction situation than in familiar surroundings. Tension results because of anxiety and anxieties exist when expectations in situations seem ambiguous.

Harkness and Keefer (2000) attempted providing an explanation for the relationship between culture and health when they observe that health and or illness are culturally defined and treated. According to this notion, Cultural meaning systems inform aspects of illness and some diseases are culture specific. This observation implies that culture is a way of life of a people which impacts on the social, economic, mental health and psychological existence of a people. A question that arise is how does culture affect the psychological health of a people? An attempts at answering this question may require an understanding of the concepts of psychological health also called psychopathology.

The term psychopathology refers to the scientific study of the causes, diagnosis, and treatment of abnormal behavior. The development of this aspect of behavior in each age classification is directly related to the changes in the people's beliefs about the causes of abnormal behavior. It becomes necessary to investigate how much beliefs precipitate and perpetuate psychopathological symptoms. Draguns, (1997) is of the view that culture and psychopathology are inextricably intertwined and that abnormal behavior can only be understood within the cultural framework within which they occur. This perspective, according to Draguns (1997), is known as cultural relativism. While the contrasting view suggests that although culture plays a role in determining the exact behavioral and contextual manifestation of abnormal behavior, there are cross-cultural similarities and even universalities, in the underlying psychological mechanisms and subjective experiences of many psychological disorders.

A poor understanding of the ways in which abnormal behavior is bound within the context of culture may lead to over-diagnosis, under-diagnosis and or misdiagnosis of distress symptoms (Painiagua, 2000), with potentially harmful consequences to the individual. In ancient times and among various culture, it is believed that behaviour was controlled by gods act, bad spirits or demons. This belief known as "Demonology" held that the devil or other evil entities take complete or partial possession of peoples' mind as a result of which each people exhibit psychopathological symptoms.

The development of psychopathological phenomena cut across cultures. In many cultures in Nigeria, abnormal behaviours were attributed to supernatural causes such as evil spirits, witchcraft and sorcery. Also, causes such as curses, violation of ancestral worship, violation of taboos and fellow men's evil machinations were recognized. In the Nigerian traditional setting, patients were treated through medical rituals which were performed to treat causes attributed to evil machination, curses, witchcraft and sorcery. Sacrifices were made to appease the gods in the case of causes due to evil spirits and others.

This study is interested in not only whether people believe in paranormal phenomena such as parapsychological claims as well as all manners of magical, occult, and other ideas such as UFO's (i.e. unidentified flying objects), astrology, déjà vu, the Lock Ness Monster, angels, the unluckiness of walking under a ladder, haunted houses, communication with plants, witches, levitation, palmistry and many others; but in how the beliefs in any one or combinations of these is or are capable of being a factor that consequently lead to the development of psychopathological symptoms. Even though it may be debatable whether each of these beliefs fall within the purview of paranormal as defined above by Thalbourne (1994), nonetheless, the definition of paranormal as offered by Tobacyk and Milford (1983) suggests that the beliefs fall within the purview of paranormal. This study therefore intends to further the advancement in the scientific understanding of paranormal beliefs which potentially could have some wide-ranging implication in the development of psychopathological disorders.

This paper intend to:

i. find out the possible main and interaction effect of culture and paranormal beliefs on psychopathological symptoms. 
ii. investigate whether there will be a significant difference in paranormal and cultural beliefs of the Yoruba and Igbo people under study.

In a study, Schriever, (2000) found out that individual can be heavily influenced by cultural factors such as family, peer group processes, dissemination of paranormal concepts in the media and formal persuasion by social institutions, e.g. the church. This may suggest that believers in paranormal phenomena may be maladjusted in some form or another, but the evidence with respect to personality dimensions is decidedly mixed in another study. Thalbourne, Dunbar and Delin (1995) found a significant positive relationship between paranormal beliefs (especially belief in PSI, witchcraft, spiritualism, precognition and traditional religion) and Neuroticism using the Revised Paranormal Belief Scale (RPBS), whereas other researches (Lester and Monaghan, 1995; Willejing and Lester, 1997) have found no such relationship. In a similar way, anxiety showed a close relation with paranormal beliefs in some studies (Okebukola, 1986; Wagner and Ratzebura, 1987), but it did not in others (Tobacyk, 1983). But a more recent study has reported significant relationship between paranormal beliefs, trait anxiety and dissociative experience (Woltradt, 1997), which mirrors findings of previous studies (Irwin, 1994; Pekala, Kumar and Marcano, 1995).

F urnham (1997) also noted further that cultural attitudes towards illness particularly affect the acceptability of professional help. The issue of acceptability of professional help is particularly important because if a cure is recommended to a patient who does not believe in the theories of the cause and cure of the illness, it is unlikely that the patient suffering from such illness may follow the guidelines for the cure or may ensure that the cure is effective. The theories of cause and cure must, of necessity, be meaningful to the patient in terms of the realities he/she understands.

\section{Participants}

\section{Methods}

Data were collected from 204 adolescents and adults comprising of the Yoruba and Igbo ethnic groups resident in Ado-Ekiti the Capital city of Ekiti-State, Nigeria. They were 103 males and 101 females who ranged in age from 14 to 65 years. The name and address of the participants were not recorded to ensure anonymity. The participants used had minimum academic qualification of Junior Secondary School but are literate enough to understand simple English language required for the understanding of the psychological instruments used in the present study.

\section{INSTRUMENT AND PROCEDURE}

Each participant was administered a questionnaire that comprise two psychological instruments.

The first is the Revised Paranormal Belief Scale (RPBS) developed by Tobacyk and Milford (1988) which contains 26 items. It is a self report scale that provides a measure of degree of beliefs in each of the seven dimensions involving traditional religious beliefs, Psi, witchcrafts, superstitions, spiritualism, extraordinary life forms, and precognition. Participants were asked to respond to all questions regarding their beliefs adjacent to paranormal belief in relation to the items on the questionnaire by putting a number next to each item to indicate how much they agree or disagree with that item starting with $1=$ Strongly disagree $2=$ Moderately disagree $3=$ Slightly disagree $4=$ Slightly agree $5=$ Moderately agree and $6=$ Strongly agree. Each item is scored on a seven point Likert scale with a higher rating indicating stronger endorsement of paranormal beliefs. The internal consistencies of the RPBS were adequate with Cronbach's Alpha's of 91, and 83 for global paranormal beliefs.

The second instrument used is the General Health Questionnaire (GHQ) developed by Goldberg (1978). It is a screening instrument aimed at detecting non-psychotic psychiatric disorders regardless of diagnosis in the community. It is a 28 item instrument which measures somatic symptoms, anxiety, insomnia, social dysfunction and severe depression. It has a cronbach's alpha coefficient reliability of the subscales which vary around 0.82 and the internal consistency of the total scale of 0.92 . Participants were instructed to answer all questions by simply underlying the answer they think nearly applies to them as at the time of responding to the questionnaire.

A score of 1,2, 3, and 4 are assigned to each of the four responses respectively. A choice of either the third (3) or fourth (4) response is considered "Positive" while 1 or 2 is considered negative. These look like a four way response scale which represent Yes or No scale. The total scores are added to give the global score for analysis.

The questionnaires were administered to the participants in their places of works, houses, and business offices. Necessary materials such as pencil, sharpener and eraser to be used in responding to the instruments were attached. The questionnaire was given to them to read after which necessary rapport was established. Participants at schools were given through their class teachers while some staff of such schools also participated. Those in the markets and shops were given directly but were asked to submit them back to a designated place within their location. All participants were asked to return the questionnaire within one week. It was easier to collect those at schools. The collections at the market places and shops were more difficult. 
A total number of three hundred questionnaires were administered, but only 276 were returned. Out of the 276, only 204 were correctly responded to. 72 questionnaires were disqualified based on errors ranging from non-completion of items, incomplete pages of instrument and outright non compliance with instructions given. Thus a response rate of $92 \%$ was achieved.

\section{Results}

2 X 2 Analysis of Variance table showing the effect of culture and paranormal beliefs on psychopathological symptoms.

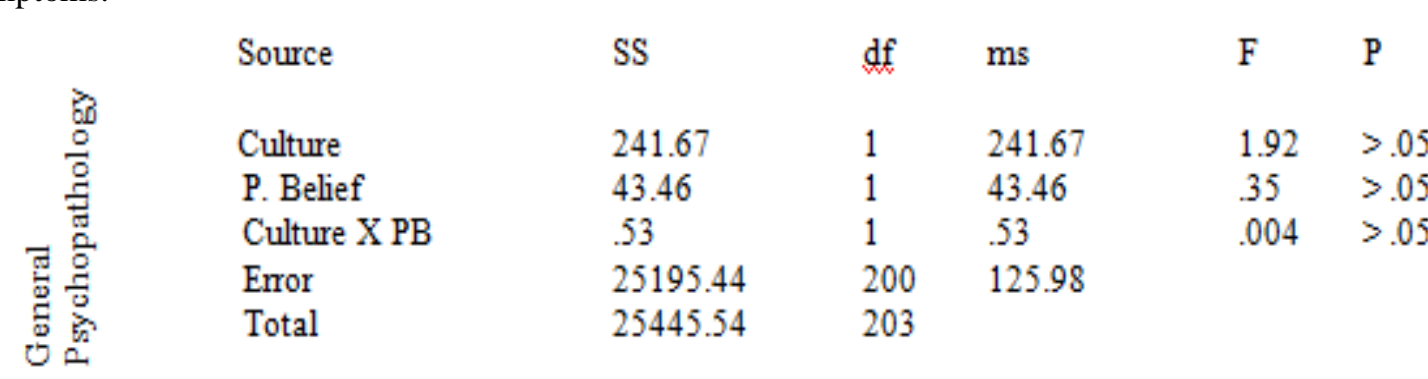

\begin{tabular}{|c|c|c|c|c|c|}
\hline \multirow{5}{*}{ 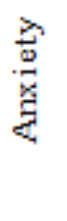 } & & 73.71 & 1 & 73.71 & 6.44 \\
\hline & P. Belief & 22.76 & 1 & 22.76 & 1.99 \\
\hline & Culture X PB & 5.92 & 1 & 5.92 & .52 \\
\hline & Error & 2289.02200 & 11.45 & & \\
\hline & Total & 2424.75203 & & & \\
\hline
\end{tabular}

$\begin{array}{lllllll}. & \text { Culture } & 14.66 & 1 & 14.66 & 1.16 & >.05 \\ \Xi & \text { P. Belief } & 34.64 & 1 & 34.64 & 2.73 & >.05 \\ \text { Culture X PB } & .055 & 1 & .055 & .004 & >.05 \\ \text { Error } & 2533.84200 & 12.67 & & & \\ \text { Total } & 2574.17203 & & & & \end{array}$

\begin{tabular}{|c|c|c|c|c|c|c|}
\hline \multirow{5}{*}{ 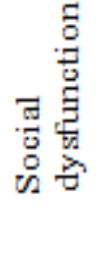 } & Culture & 9.02 & 1 & 9.02 & .96 & $>.05$ \\
\hline & P. Belief & 17.98 & 1 & 17.98 & 1.91 & $>.05$ \\
\hline & Culture X PB & .32 & 1 & .32 & .034 & $>.05$ \\
\hline & Error & 1884.14200 & 9.42 & & & \\
\hline & Total & 1906.29203 & & & & \\
\hline \multirow{5}{*}{ 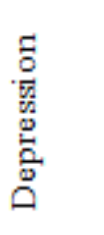 } & Culture & 85.34 & 1 & 85.34 & 7.03 & $<.05$ \\
\hline & P. Belief & 84.85 & 1 & 84.85 & 6.99 & $<.05$ \\
\hline & Culture X PB & 3.29 & 1 & 3.29 & .27 & $>.05$ \\
\hline & Error & 2428.25200 & 12.14 & & & \\
\hline & Total & 2566.04203 & & & & \\
\hline
\end{tabular}

From the above, it is revealed that there is a main effect of culture on anxiety $(\mathrm{F}(1,203)=6.44, \mathrm{P}<.05)$ and depression $(\mathrm{F}(1,203)=7.03 \mathrm{P}<.05)$. Also, there is a significant main effect of paranormal belief on depression $(\mathrm{F}(1,203)=6.99 \mathrm{P}<.05)$. This shows that culture has significant main effects on anxiety and depression dimension of psychopathological symptoms but not on global symptoms, ditto paranormal beliefs on depression. Independent t-test table showing the difference between the two ethnic groups (Yoruba and Igbo) on paranormal belief and psychopathological symptoms. 


\begin{tabular}{|c|c|c|c|c|c|c|c|c|}
\hline Variable & & $\mathbf{N}$ & $\mathbf{x}$ & SD & $\mathrm{SE}$ & df & $\mathbf{t}$ & $\mathbf{p}$ \\
\hline 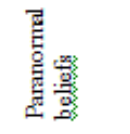 & $\begin{array}{l}\text { Yoruba } \\
\text { Igbo }\end{array}$ & $\begin{array}{l}107 \\
97\end{array}$ & $\begin{array}{l}90.68 \\
96.07\end{array}$ & $\begin{array}{l}13.53 \\
14.48\end{array}$ & $\begin{array}{l}1.31 \\
1.47\end{array}$ & 202 & 2.75 & $<.05$ \\
\hline 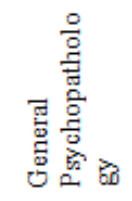 & $\begin{array}{l}\text { Yoruba } \\
\text { Igbo }\end{array}$ & $\begin{array}{l}107 \\
97\end{array}$ & $\begin{array}{l}40.77 \\
38.75\end{array}$ & $\begin{array}{l}17.86 \\
10.37\end{array}$ & $\begin{array}{l}1.47 \\
1.05\end{array}$ & 202 & 1.29 & $>.05$ \\
\hline 总 & $\begin{array}{l}\text { Yoruba } \\
\text { Igbo }\end{array}$ & $\begin{array}{l}107 \\
97\end{array}$ & $\begin{array}{l}10.77 \\
9.32\end{array}$ & $\begin{array}{l}3.63 \\
3.09\end{array}$ & $\begin{array}{l}.35 \\
.31\end{array}$ & 202 & 3.05 & $<.05$ \\
\hline 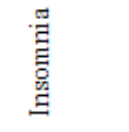 & $\begin{array}{l}\text { Yoruba } \\
\text { Igbo }\end{array}$ & $\begin{array}{l}107 \\
97\end{array}$ & $\begin{array}{l}10.09 \\
9.76\end{array}$ & $\begin{array}{l}3.60 \\
3.63\end{array}$ & $\begin{array}{l}35 \\
.36\end{array}$ & 202 & 0.66 & $>.05$ \\
\hline 营总 & $\begin{array}{l}\text { Yoruba } \\
\text { Igbo }\end{array}$ & $\begin{array}{l}107 \\
97\end{array}$ & $\begin{array}{l}10.43 \\
10.70\end{array}$ & $\begin{array}{l}3.19 \\
2.92\end{array}$ & $\begin{array}{l}.31 \\
.29\end{array}$ & 202 & -0.63 & $>.05$ \\
\hline 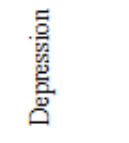 & $\begin{array}{l}\text { Yoruba } \\
\text { Igbo }\end{array}$ & $\begin{array}{l}107 \\
97\end{array}$ & $\begin{array}{l}9.89 \\
8.92\end{array}$ & $\begin{array}{l}3.73 \\
3.29\end{array}$ & $\begin{array}{l}36 \\
-33\end{array}$ & 202 & 1.99 & $<.05$ \\
\hline
\end{tabular}

From the table above, it is revealed that there is a significant difference between the two ethnic groups (Yoruba and Igbo) on paranormal belief $(\mathrm{t}(202)=2.75 \mathrm{P}<.05)$ Also there is a significant difference between Yoruba and Igbos on anxiety symptoms $(t(202)=3.05 \mathrm{P}<0.5)$, and on depression $(\mathrm{t}(202)=1.99, \mathrm{P}<.05)$.

\section{Discussion}

This cross-cultural research investigated the influence of paranormal beliefs and culture on psychopathological symptoms. Findings showed that out of four dimensions of psychopathology: somatic symptoms, anxiety, insomnia, social dysfunction and severe depression; paranormal beliefs significantly influenced only anxiety and depression. There was also a significant main effects of culture and paranormal beliefs on psychopathological symptom on anxiety and depression dimension. The result of this study agreed with Okebukola, (1986). Wagner and Ratzeburg, (1987) which showed a close relationship between paranormal beliefs and anxiety but did not significantly relate to other dimension of psychopathological symptoms. Tobacyk, (1983).

Another study reported significant relationship between paranormal beliefs, trait anxiety and dissociative experiences (Wolfradt, 1997) which mirrors findings of previews studies (Irwin, 1994; Pekala, Kumar and Marcano, 1995). The significant main effect of culture and paranormal beliefs on psychopathological symptoms as confirmed in this study possibly agreed with the observation of Matsumoto (2002) that there is a continual tension between individual behaviours within any culture and the cultural labels that are used to describe them. The result showed a significant main effect of paranormal belief on depression. These indications revealed themselves at individual level, but no significant joint or interaction effect was discovered on any. The first aspect of this finding which confirmed a significant main effect of culture on anxiety and depression can also be discussed in consonance with a study by Matsumoto and colleagues (1999) when testing the effect of cultural discrepancies on physical health. The discrepancies between self and society 
were tested among university undergraduates by asking what their personal values were, as well as their perceptions of society's value. They were also made to complete a scale assessing strategies for coping with stress, anxiety, depression and other mood measures and scales assessing physical health and psychological well being. The result indicated that discrepancies between self and society's cultural values were significantly correlated with all eight coping strategies. These coping strategies were significantly correlated with depression and anxiety. It also shows that the higher scores on anxiety were strongly correlated with greater health problems.

In another dimension, Triandis (1992) suggested that culture, specifically, social support, plays an important role in mediating stress, which affects health. They examined the relationship between cultural difference and the incidence of a particular disease state (heart disease). Collectively, the study suggests the important role of socio-cultural factors in contributing to health and disease. It should be noted however that, not only do cultural definitions influence the interpretation of an event as stressful, but also an understanding of the role of life events depends on the models and links used. Usually omitted in the causal chain of events are the broad politico-economic processes, which help structure the micro-situations within which individuals interact. These micro-forces and social relationships are hidden by the focus on objective event and the mitigating characteristics of individual (Nzewi 1989). This perhaps may be responsible for the differences in sociopsychological phenomena between Yoruba and Igbos which are noticeable in their distinct values, attitudes, beliefs and behaviours. .

Furthermore, the differences in Igbos and the Yorubas in regard to anxiety and depression can be explained in the context of the words of Nzewi (1989), "the major issue in the understanding of diagnostic categories and aetiological factors in other cultures is not merely discovering equivalence of concepts cross-culturally or matching patterns of symptoms. More important than these factors is the understanding of the vocabulary, belief system and the perceptions of the patients. The aetiology and symptom presentation of patients are often functions of culture. It is interesting to note that ethnic background has been included in some investigations of paranormal beliefs. In an individual studies by Murphy (1982), and Mitchell (1973) it was observed that blacks people have a higher belief in an aspect of paranormal (precognition) than did whites people. These researchers also noted in a sample of university students that, blacks showed stronger belief than Whites in spiritualism, superstitions, and witchcraft, Tobacyk, (1988).

Also, another finding revealed a significant difference between the Yoruba and Igbo ethnic groups on anxiety symptom. But no significant difference was found on other dimensions of psychopathological symptoms. The difference found between the two ethnic groups may be in consonance with findings from crossculture studies done in the past. For example, a cross-cultural study of depression however, document wide variations in expression of psychopathology of this disorder. It was discovered that some cultural groups in Nigeria are less likely to report extreme feelings of worthlessness and guilt-related symptoms while others such as Chinese are more likely to report somatic complaints. Kleinman, (1988) and Leff (1977) buttress this finding by saying cultures vary in terms of their differentiation and communication of emotional terminology and also in how they experience and express depression.

\section{Conclusion and Recommendation}

This study has been able to establish that a significant influence exist between paranormal beliefs and incidence of psychopathology. It was also discovered that there is a significant main effect of culture on anxiety and depression. The study vividly revealed that cultural differences exist when paranormal beliefs are compared between two ethnic groups since there exist a significant difference between the Yorubas and Igbos on paranormal belief scale. Result shows that there is a significant difference between Yorubas and Igbos on anxiety and depression symptoms.

The study therefore has demonstrated that it is important to consider people's belief and practices when designing a health program for a culture specific group since each cultural group may have different perception of the origin or causes of illness while the therapeutic methods adopted by different groups may also differ.

In the light of above discovery, psychopathological intervention should merge aspects of traditional psychopathology with culture specific methods and beliefs to produce unique systems of healing. For example, Sato (1998) suggested that culturally indigenous therapies can be augmented successfully with aspects of contemporary cognitive and behavioural therapies. More importantly, in designing any health policy, the methodology should be localized in agreement with the beliefs of the population concerned for a meaningful success to be achieved. This submission is in agreement with Feyisetan and Adeokun (1992), that the success of any health policy depends very much on how much effort is put into streamlining beliefs that are at variance with medical principles. 


\section{Reference}

[1]. Bandura, A (1986) Social Foundations of thought and action. A Social Cognitive Theory. Englewood Cliffs, N.J: Prentice Hall.

[2]. Barry, H. (1980). Description and uses of Human Relations Area files. In H.C. Triandis of J.W Barry (Eds), Handbook of Crosscultural Psychology: vol. 2 Methodology (pp.445-478). Boston: Aliyu of Bacon.

[3]. Bell, Earl H. (1961) Social Foundations of Human Behaviours New York. Harper, Wadsworth Publishers.

[4]. Benedict, R. (1961) Patterns of Cultures London. Routledge and Kegan Paul.

[5]. Berry, J.W. Poortinga Y.H, Segall, M.H, \& Dasen, P.R (1992): Cross-culture Psychology: Research and Applications. New York: Cambridge University Press.

[6]. Broad, C.D (1953): The relevance of physical research to philosophy. In J. Ludwig (Eds): Philosophy and parapsychology (pp. 4363) Buffalo, NY: Prametheus.

[7]. Draguns, J. (1997); Abnormal behaviour patterns across Cultures: Implications for Counseling and Psychopathology. International Journal of Inter-Cultural Relations, 21(2), 213-248.

[8]. Feyisetan, B.J, Adeokun, L (1992): Impact of Childcare and Disease Treatment on Infant Mortality. Pp

[9]. 145-159:- Mortality and society in Sub-Saharan Africa, ed. E. Van de Walle. G Pison and Mpembnele sala-diakanda. Oxford: Clarendon Press.

[10]. Furnham (1997): Overcoming neurosis. Lay attributions of cure for five specific disorders. Journal of Clinical Psychology, 53,595604.

[11]. Harkness, S. and Keefer, C.H. (2000); Contributions of cross-cultural psychology to research and interpretations in education and health. Journal of Cross-cultural Psychology, 31, 92-109.

[12]. Irwin, H.J (1994): Paranormal beliefs and proneness to dissociation. Psychological Reports, 75, 13444-1346.

[13]. Kleinman, A (1988); Rethinking psychiatry: From cultural category to personal experience. New York: Free Press.

[14]. Lester, D. \& Monoghan, K. (1995); Belief in the paranormal and personality: Perceptual and Motor Skills, 81, 114.Willing, B.T \&s

[15]. Levine, R. A. (2009) Culture, behaviour and personality: introduction to comparative study of psychological adaptation. Chica go Aldine.

[16]. Malpass, R.S. (1993 August). A Discussion of the ICAI. Symposium presented at the Annual Convention of the American Psychological Association, Toronto.

[17]. Markel, P (2009). Cultural differences impact workplace communical http://www.alliancetac.com/?PAGE ID = 2560.

[18]. Matsumoto, D. (2002). The New Japan: Debunking seven Cultural Stereotypes. Yarmouth, M.E: Intercultural.

[19]. Mischel, W. (1973): Toward a cognitive social learning reconceptualization of personality Psychological Review 80, $252-283$.

[20]. Murdock, G.P, Ford, C.S, \& Hudson, A.E (1971), Outline of cultural materials (4th Ed). New Haven, CT: Human Relations Area Files.

[21]. Murphy, H.B.M (1982): Culture and schizophrenia. In 1.AI-Issa (Ed), Culture and psychopathology (pp. 221-249). Baltimore: University Park Press.

[22]. Nzewi, N. E. (1989); Cukltural factors in the classification of psychopathology in Nigerian. In K peltzer and p. O. Ebigbo (Eds). Clinical Psychology in Africa. Enugu, WGAP, pp. 208 - 216.

[23]. Okebukola, P.A (1986); Relationship between anxiety, belief system, and creativity. Journal of Social Psychology, 126, 815-816.

[24]. Paniagua, F.A (2000). Culture Bound syndromes, cultural variations and psychopathology. In I. Cuellar \& F.A Paniagua (Ed), handbook of multicultural mental health assessment and treatment of diverse populations (pp.139-169) San Diego: Academic Press.

[25]. Pekala, R.J. Kumar, V.K \& Marcano, G. (1995); Anomalous Paranormal experiences, hypnotic-susceptibility, and dissociation. Journal of the Society for Physical Research, 89, 313-332.

[26]. Samova, L. A. and Richard E. Porter Editors (1971) Intercultural Communication: A reader. Wadsworth Publishing Company, Inc. Belmonth California.

[27]. Sato, T. (1998): Agency and Communion: the relationship between therapy and culture. Cultural Diversity and Mental Health, 4, 278-290.

[28]. Schriever, F. (2000): Are there different cognitive structures behind paranormal beliefs? European Journal of Parapsychology, 15, 46-47.

[29]. Smith, A L. (1973). Trans-racial Communication. New York: Prentice-Hall Inc.

[30]. Thalbourne, M. A. (1994); Belief in the paranormal and its relationship to schizophrenia related measures: A confirmatory study. British Journal of Clinical Psychology, 33, 78-80

[31]. Thalbourne, M.A Dunbar, K.A \& Delin, P.S (1995); An investigation into correlates of belief in the paranormal. Journal of the Society for Physical Research, 89, 215-231.

[32]. Tobacyk, J. S Milford, G. (1983); Belief in paranormal phenomena: assessment instrument development and implications for personality functioning. Journal of Personality and Social Psychology. 44, 1029-1037.

[33]. Tobacyk, J.J. (1988); A revised paranormal belief scale. Unpublished Manuscript. Louisiana Tech University Ruston, L.A

[34]. Triandis, H.C, (1972); The analysis of subjective culture. New York: Wiley.

[35]. Tsa-Tsala (1997): Beliefs and disease in cameroon. In S.N. Madu, P.K. Baguma and Pritza, A. (eds) Psychotherapy in Africa: First investigation. Vienna,b world council for psychotherapy, pp. 44

[36]. Wagner, M.W \& Ratzeburg, F.H (1987); Hypnotic suggestibility and paranormal belief. Psychological Reports, 60, 1069-1070.

[37]. Willing, B.T \& Lester, D. (1997); Paranormal beliefs and personality scores of high school students. Perceptual and Motor Skills, 85,938 .

[38]. Wolfradt, U. (1997): Associative Experiences, Trait Anxiety and Paranormal Beliefs. Personality and Individual Differences, 23, $15-19$. 